\title{
Algunos aspectos fundamentales en la teoría general de títulos-valores en Colombia*
}

\author{
Some fundamental aspects in the general theory of titles-securities in Colombia
}

Libardo Quintero Salazar ${ }^{1}$ CvLAC

Fecha correspondencia:

Recibido: 23 de abril de 2019.

Revisión: 10 de octubre de 2019.

Aceptado: 17 de octubre de 2019

\section{Forma de citar:}

Quintero, Libardo. Algunos aspectos

fundamentales en la teoría

general de los títulos - valores en

Colombia. Revista CES Derecho. Vol.

10, №. 2, julio - diciembre de 2019,

654-674.

Open access

Términos de uso

Licencia creative commons

Etica de publicaciones

Revisión por pares

Gestión por Open Journal System

DOl: http://dx.doi.org/10.21615/

cesder. 10.2.6

ISSN: 2145-7719

Sobre el artículo:

*El presente artículo se trata de

un documento de reflexión no

derivado de investigación.

Sobre los autores:

1. Abogado de la Universidad

Católica de Oriente, especialista

en derecho comercial de la

Universidad Pontificia Bolivariana,

Magíster en derecho privado

patrimonial de la Universidad de

Salamanca-España, Magíster en

derecho procesal de la Universidad

de Medellín, doctorando en

derecho privado de la Universidad

\section{Resumen}

Una de las materias con mayores tecnicismos en la carrera de derecho, es sin duda la atinente a los títulos-valores. Ello hace necesario, que el estudiante o cualquier operador jurídico deba tener herramientas adecuadas para que pueda acercarse sin prejuicios al tema de estudio. Para ello se propone un escrito claro y conciso, especialmente acompañado de casuística, que, de cuenta de algunos de los aspectos problemáticos más comunes en la teoría general de los títulos-valores y como resolverlos de manera pacífica.

Palabras clave: Título-valor, literalidad, incorporación, legitimación, autonomía, firma.

\section{Abstract}

One of the subjects with greater technicalities in the law career, is undoubtedly the subject of securities. This makes it necessary for the student or any legal operator to have adequate tools so that he can approach the subject of study without prejudice. For this, a clear and concise writing is proposed, especially accompanied by casuistry, which, on account of some of the most common problematic aspects in the general theory of securities and how to solve them peacefully.

Keywords: Title-value, literalness, incorporation, legitimation, autonomy, signature.

\section{Introducción}

Los títulos-valores son bienes mercantiles de gran usanza en nuestro medio. Son miles las obligaciones que a diario se incorporan en estos instrumentos, desde un préstamo no muy cuantioso representado en una letra de cambio, hasta una factura de venta que incorpore una suma considerable por la venta o prestación de servicios empresariales. En uno u otro caso, deberán aplicarse e interpretarse con la misma intensidad las normas jurídicas sobre los títulos-valores.

Lo que se propone en este artículo, es llegar al lector con un lenguaje sencillo y directo, (especialmente a los estudiantes de derecho), sobre temas fundamentales que se abordan en la teoría general de los títulos-valores. En ese sentido, el mayor mérito del escrito será que el lector encuentre en él a partir de un estilo diferente, una lectura agradable, que le proporcione 
de Salamanca-España; docente investigador del Grupo de Investigaciones Jurídicas de la Facultad de Derecho de la Universidad Católica de Oriente. elementos que le permitan abordar con meridiana claridad, un tema muy particular que por su tecnicismo y prosa legal suele hacerse diferente al estudio de otras áreas del derecho mercantil.

Es así como en el presente documento se exponen dos capítulos, el primero, sobre las características generales de los títulos-valores y el segundo sobre aspectos particulares que son problemáticos en el estudio de la teoría general de los títulos-valores, tales como la firma, los títulos-valores con espacios en blanco, la prescripción, entre otros.

Si bien podría decirse que sobre el tema de los títulos-valores pueden existir los suficientes textos, no obsta para que el lector menos avezado o que quizás necesite recordar algunos aspectos básicos, pueda dar una mirada a lo que aquí se escribe y si a bien lo tiene, luego se sumerja en un estudio profundo sobre la materia. Con todo, quien escribe lo hace con su propio estilo, el que le ha proporcionado la academia y más de una década de ejercicio profesional.

\section{Conceptualización general sobre los títulos-valores}

El Código de Comercio (en adelante C.co.) en su artículo 519 trae una definición de lo que debe entenderse por Título-valor, así: "Los títulos-valores son documentos necesarios para legitimar el ejercicio del derecho literal y autónomo que en ellos se incorpora. Pueden ser de contenido crediticio, corporativos o de participación y de tradición o representativos de mercancías".

Por ahora, y antes de desmenuzar la anterior definición a partir de la descripción de las características contenidas en aquella (legitimación, literalidad, autonomía e incorporación), intentaremos preliminarmente una definición sencilla. Podríamos decir que los títulos-valores son documentos que pueden representar derechos de diferente índole, tales como: exigir sumas de dinero, reclamar mercancías, o participar en una sociedad mercantil, pero en todos los casos únicamente de acuerdo a las condiciones descritas en ese documento. Obviamente, al estar representadas las obligaciones o tomar forma en un título-valor, las hará regir por sus propias normas y las que se encuentran en el Código de Comercio.

Pensemos por ejemplo en un contrato de mutuo o préstamo de dinero entre $B$ y $A$, en dos contextos:

a. En el préstamo no se involucra un título-valor.

b. En el préstamo se involucra un título-valor.

En el primer evento, podemos decir que el contrato es perfecto desde el mismo momento en que $B$ el prestamista le entrega la suma de dinero a $A$. Al existir el contrato y en este caso particular, un contrato unilateral, $A$ está obligado a pagar la suma de dinero el día de su exigibilidad, y en contraste, $B$ tiene derecho a solicitar el pago de dicha suma de dinero a $A$. Me quiero quedar con esto último en estos momentos, o sea, que $B$ tiene un derecho de crédito sobre $A$. Ese derecho hace parte de su patrimonio, eso quiere decir, que $B$ además de su casa o su carro, también tiene un derecho de crédito. Pero la pregunta ahora sería: ¿dónde está materialmente ese derecho? La verdad, hasta ahora según se ha planteado el ejemplo, sabemos que el derecho de crédito existe, pero no tiene una presencia material, por lo que en caso de una negativa de pago por parte de $A$ y en un eventual proceso judicial donde se busque su cobro, se tendrá que utilizar algún medio de prueba como una confesión o testimonios. 
Para explicar el segundo evento, continuemos con el mismo ejemplo, pero en esta ocasión $B$ le dice a $A$ que para que le garantice el pago de la suma de dinero suscriba un título-valor, digamos un pagaré en beneficio del mismo $B$. ¿qué cambia? Pues de entrada podemos decir que el derecho de crédito toma forma o toma posesión en el documento, no en vano en medio de la expresión título-valor existe un guion "-"1 que en este caso, significa unión entre un documento y un derecho, como un todo unitario. Si preguntaran ¿dónde se encuentra el derecho? No habría lugar a dudas que bastaría con la exhibición de este, para advertir que ahí en el mismo documento, efectivamente se encuentra, por tal motivo, de su existencia depende el goce del derecho.

Esta ficción, podemos explicarla con un billete que representa el valor de 100 mil pesos colombianos, podríamos preguntarnos ¿cuánto vale el billete como papel? Me refiero a su valor de creación y diseño; según el Banco de la Republica a 2018, vale 120 pesos (Revista Dinero)². Ahora, cuando nos acercamos a comprar con el billete, ese documento, que vale 120 pesos como papel, jrepresenta 100 mil pesos! y ello, porque convencionalmente hemos aceptado que los billetes representan un valor económico, con el ánimo de dinamizar la economía y el mercado. Algo similar ocurre con los títulos-valores, intereses económicos de circulación de la riqueza, han permitido que tales documentos representen derechos de variada índole (no solo de pagar sumas de dinero, sino inclusive mercancías). En fin, para redondear el supuesto e irlo concluyendo, la suma de dinero que le prestó $B$ a $A$, está incorporado en el documento, en ningún otro lugar; la única prueba de su existencia está en él ${ }^{3}$, de tal forma, que el día del vencimiento, ante la negativa de pago, podrá iniciar un proceso ejecutivo para su recaudo, solo con dicho documento, no se necesitan otras pruebas.

Pero dicho derecho por supuesto no se agota solo en la posibilidad de cobro al vencimiento, no, $B$ también puede negociar o realizar transacciones económicas con el título-valor, inclusive puede pagar con dicho instrumento obligaciones contraídas con anterioridad (Art. 882 C.co). Por ejemplo, podría comprar un carro en una empresa de automóviles y ofrecer como forma de pago el derecho de crédito que está incorporado en el título-valor. Para ello tendría que negociarlo, en este caso, mediante endoso (tal cual lo explicaremos a continuación) por lo que la empresa se constituiría en la nueva legítima tenedora del título-valor, pero con un elemento adicional, mantendrá como responsable del pago a $B$ en caso de que $A$ no pague. Lo inmediatamente dicho significa que los títulos-valores no solo facilitan la garantía de los derechos que en ellos se incorpora, sino que permite que los derechos allí representados circulen con facilidad.

Para continuar con la explicación de la definición normativa, de allí también se sustraen las características de los títulos-valores y que, en resumen, son: Legitimación, literalidad, autonomía e incorporación. Vamos a explicarlos de forma breve.

\section{La legitimación}

Es la facultad que posee el tenedor del título-valor, para ejercer los derechos representados en el documento, y esa facultad se adquiere por (a) tener el título materialmente y (b) haberlo adquirido conforme a las leyes de circulación. La legitimación es para el acreedor una carga, pero a la vez una prerrogativa. Es una carga, porque para poder ejercer el derecho debe exhibir el documento (Art. 624 C.co) y es una prerrogativa, porque quien se encuentre legitimado se considera dueño, sin que ni siquiera

1. Semánticamente significa la unión de dos palabras, que, aunque independientes de forma natural, deben leerse de forma inescindible.

2. Información rescatada de: https://www.dinero.com/economia/articulo/cuanto-cuesta-fabricar-billetes-en-colombia/257071

3. Si el título-valor, se pierde, se destruye o se vuelve por alguna razón ininteligible, es posible iniciar un proceso de cancelación y reposición de título-valor regulado en los artículos 802 y siguientes del Código de Comercio y 398 del Código General del Proceso. 
tenga que demostrar que verdaderamente es el propietario, pues la ley presume que lo es (Tena, 2001). Esto permite que el acreedor no tenga que demostrar más para ejercer el derecho, pero a su vez, también beneficia al deudor, pues le basta solo con identificar al legítimo tenedor sin que tenga que averiguar para hacer un buen pago, si los endosos que le antecedieron al legítimo tenedor eran auténticos o no (Art. 662 C.co). Lo anterior permite una adecuada y ágil circulación, pues si se tuviera que dar cuenta de la autenticidad de cada endoso puesto en un título-valor, el ejercicio del derecho se haría lento e incierto, y a su vez el deudor, podría hacer un pago temeroso.

Dicho esto, pasemos a continuación a indicar las leyes de circulación.

\section{a. Títulos-valores al portador}

Son aquellos títulos-valores en los que no se especifica la persona del beneficiario, no se expiden a favor de persona determinada (Art. 668 C.co.). Su tradición o negociación se producirá por la sola entrega material del título.

\begin{tabular}{c}
\hline Forma de circulación \\
\hline Con la entrega Material \\
\hline
\end{tabular}

Ejemplo: "Yo A me comprometo a pagar 2.000.000 de pesos el día X". A, se está comprometiendo a pagar, a quien tenga el título materialmente. Si $A$ se lo entrega a $C$ con la intención de hacerlo negociable, este será el beneficiario del título, y si C quiere negociarlo con $D$, tan solo tiene que entregarle el título-valor. Con el solo hecho de tener el documento materialmente, está legitimado porque lo adquirió (D) conforme a las leyes de circulación y puede cobrarle a A cuando la obligación se haga exigible.

\section{b. Títulos-valores a la orden}

Son aquellos que se expiden a favor de una persona determinada (art 651 C.co). Ejemplo: "Yo A me comprometo a pagar a la orden de B 1.000.000 de pesos, el día X". $B$ en este caso es el beneficiario y como tal podrá cobrarlo al vencimiento o negociarlo con otra persona; si decide esto último, por ejemplo con $C$, se requiere el endoso y la entrega material por parte de $B$ a $C$ para que se perfeccione la negociación y nueva legitimación.

\begin{tabular}{ll}
\hline Forma de circulación \\
\hline -Endoso. \\
-Y entrega Material. \\
\hline
\end{tabular}

Endoso: Acto jurídico unilateral por el cual el actual tenedor de un título-valor pone a otra persona en su situación con efectos plenos o limitados. Siguiendo con el ejemplo, $B$, antes de entregar el título a $C$, debe escribir detrás del mismo "Endoso a C" y posteriormente firmar ( $C$ no tiene que firmar). $Y$ así se entiende que el nuevo legítimo tenedor es $C$.

Con este ejemplo, referenciamos el llamado endoso en propiedad que es el que transfiere el dominio del derecho incorporado, pero existen otros endosos, como el en procuración, que no transfiere el dominio del derecho incorporado, sino que tan solo faculta al tenedor para cobrar en nombre de otro. Lo práctico de este endoso, es que, para realizar su cobro, no se necesita poder especial, pues sus prerrogativas 
se entienden implícitas, (art. 658 C.co). Este tipo de endoso debe expresarse en el documento como en "procuración" o "para el cobro". Ejemplo: A otorga un pagaré a la orden de $B$. $B$, pretende iniciar un proceso en contra de $A$ para el recaudo del derecho incorporado, para lo cual contrata al abogado C. Para legitimar a $C$ solo para el cobro, lo más práctico es endosarle el título-valor en procuración. Así, lo que recaude $C$ será para $B$, quien sigue siendo el propietario del documento.

\section{c. Títulos-valores nominativos}

Son aquellos que se giran o se otorgan a favor de una persona determinada, pero esta persona determinada debe estar inscrita en el registro que lleve el creador del título.

\begin{tabular}{l}
\hline Forma de circulación \\
\hline -Endoso. \\
-Entrega Material. \\
-Cancelación del actual tenedor del título. \\
-Inscripción del nuevo beneficiario del título. \\
\hline
\end{tabular}

Ejemplo: Acción de una sociedad anónima. Para negociarla se necesita la entrega material, el endoso, cancelación del beneficiario anterior e inscripción del nuevo beneficiario. En este caso al legitimarse el nuevo socio, estaría siendo acreedor ante la sociedad comercial, de unos derechos políticos (votar) y económicos (recibir dividendos).

Para terminar este ítem sobre la legitimación, se debe indicar que es posible ser dueño de un título-valor sin ser legítimo tenedor. Pero esto implica tener unos derechos de inferior categoría a los que puede tener un legítimo tenedor propietario. En efecto, el propietario no legítimo tenedor, verbi gracia una persona que, en vez de recibir mediante entrega y endoso, recibió por una adjudicación en un remate o en una sucesión, si bien tiene el documento materialmente, no lo recibió del anterior tenedor y mucho menos por endoso. En este evento, aunque el artículo 652 del C. co, expresa que puede ejercer los derechos inherentes al documento, no tiene derechos autónomos. En cambio, el propietario legítimo tenedor, no solo tiene los derechos inherentes al documento, sino que además tiene derechos autónomos. No obstante, lo anterior, el artículo 653 C.co, permite al propietario no legítimo tenedor convertirse en propietario legítimo tenedor si inicia un proceso de jurisdicción voluntaria y le demuestra al juez que, aunque propietario, no adquirió de forma regular el título-valor, para ello el juez impone al final del proceso una constancia en el título que equivaldría a un endoso. Para entender lo referente a los derechos autónomos y por ende lo que hasta aquí se planea, se invita a revisar más adelante la característica de la autonomía.

\section{Literalidad}

Como el título-valor está contenido en un documento, del mismo se debe desprender de manera clara, cuál es el alcance de sus obligaciones, las que correlativamente se convierten en los derechos del legítimo tenedor (art.626 C.co). El derecho se mide por la letra del documento, por lo que dice expresamente en él, su extensión y demás circunstancias de lo literalizado, obligan en esa forma al deudor (Ahumada, 2007). Obviamente, la literalidad generará derechos y desprenderá obligaciones, siempre y cuando el derecho incorporado contemple elementos que estén dentro de los límites legales (por ejemplo, aunque un título-valor contemple el pago de intereses por encima de las tasas permitidas, no podrán exigirse tal cual quedaron literalizados). 
Ejemplo: “A, firma un título-valor a favor de $B$ por $\$ 1.000 .000$ a pagarse el 27 de marzo de 2011". El título solo podrá exigirse ese día y por ese monto y a ese obligado. La literalidad se rige por el artículo 626 C.co. La literalidad es pues, una carta de navegación, que implica que solo es válido lo que aparezca consignado en el título, es una seguridad para posteriores tenedores, que podrán determinar el alcance de sus derechos y también para el deudor para comprobar el alcance de su obligación.

Esto implica que en la práctica un título-valor no puede constituirse a partir de un título ejecutivo complejo ${ }^{4}$, es decir, con otros documentos extraños a él. Solo de forma excepcional se permite complementar el título-valor con otros documentos diferentes al principal, como en el caso de los avales ${ }^{5}$ y en las aceptaciones de facturas de venta ${ }^{6}$, pero bajo la condición que hagan expresa mención a la obligación principal. En los demás casos, se insiste, la única prueba de la obligación cambiaria es el mismo documento.

Un aspecto bien importante a resaltar, es el que tiene que ver con los abonos al capital que hace el deudor. No en pocas ocasiones el deudor hace pagos al capital y estos no quedan plasmados en el título-valor. El riesgo consiste justamente en que los abonos deben expresarse en el título-valor para dejar claro la modificación al derecho incorporado. Lo lógico es, que si inicialmente el título-valor representaba $\$ 10.000 .000$ de pesos, al hacer un abono de $\$ 2.000 .0000$ de pesos y ese se rubrica, de inmediato se notará que la literalidad varió, pues ahora el derecho incorporado es de $\$ 8.000 .000$ de pesos. Si no se deja constancia de tal abono, la literalidad dará la apariencia de que se siguen debiendo los $\$ 10.000$.000 millones de pesos. Pensemos justamente en que $A$ le abona a $B \$ 2.000 .000$ de pesos y ese último solo procede a entregar un recibo de pago, pero no deja constancia de tal abono en el documento. Posteriormente, $B$ endosa en propiedad a $C$ el título-valor, este último quien vale decir, está de buena fe exenta de culpa. Al vencimiento, $C$ inicia el respectivo proceso ejecutivo en contra de $A$. La pregunta obligada es si $A$ puede proponer a $C$ como excepción de mérito o fondo el pago parcial aportando como prueba el recibo de pago; la respuesta es no. El artículo 784 del C.co establece de forma taxativa las excepciones de mérito que se pueden proponer frente a una acción ejecutiva con base en un título-valor y en el numeral 7 dice, que el pago parcial puede proponerse, siempre y cuando conste en el título. De manera tal, que en salvaguarda de la seguridad jurídica que busca imperar por intermedio de la literalidad, no se permite proponer pagos que no pudieron ser advertidos por el nuevo legítimo tenedor. Para redondear el ejemplo, es lógico que $B$ será responsable frente a $A$ frente a ese pago ya realizado, pero para ello, este último tendrá que iniciar eventualmente un proceso de conocimiento para recuperar aquel dinero. Ahora, tampoco podemos pasar de largo, que sucedería si $B$ no hubiese endosado el documento a $C$, sino que lo hubiese cobrado él mismo, pues en este evento, A si hubiese podido proponer con éxito la excepción de pago parcial, fundamentado en el mismo artículo 784 numeral 13 que permite proponer todas aquellas excepciones personales relacionadas directamente entre las partes.

\section{Autonomía}

Un título-valor siempre debe tener una causa, o, dicho de otra manera, un negocio de fondo que justifique su creación o su transferencia. Si $A$ para garantizar el pago de una compraventa a $B$ suscribe una letra de cambio en su beneficio, el negocio causa o que

4. La Sección Tercera del Consejo de Estado, M.P. Myriam Guerrero de Escobar, dijo en Sentencia del 31 de enero de 2008: "El título ejecutivo bien puede ser singular, esto es, estar contenido o constituido en un solo documento, como por ejemplo un título valor (v.gr. letra de cambio, cheque, pagaré, etc.); o bien puede ser complejo, cuando quiera que esté integrado por un conjunto de documentos, como por ejemplo-entre otros-por un contrato, más las constancias de cumplimiento o recibo de las obras, servicios o bienes contratados, el reconocimiento del co-contratante del precio pendiente de pago el acta de liquidación, etc". 5. Un aval, es una garantía personal que permite a una persona garantizar la obligación de un obligado de manera total o parcial (ver arts. 633 y sgts C.co). 6. Sobre las facturas de venta y su aceptación ver artículos 772 y siguientes C.co. 
le dio vida a la letra es la compraventa del inmueble. Si luego $B$ compra una moto y entrega como forma de pago la letra de cambio (endosándola) a $C$, el negocio que dio lugar a la transferencia es la compraventa de la moto. Como podemos observar, sobre el mismo título-valor tenemos dos negocios jurídicos (pueden ser más). La autonomía lo que busca es dar tranquilidad al legítimo tenedor de que una vez adquiera de forma regular el título-valor, aquellos negocios jurídicos que no tuvieron nada que ver con el negocio en el que él participó, no le afectará su derecho, pue se insiste, se considera un derecho autónomo. En otras palabras, los vicios del consentimiento u otras vicisitudes provenientes del contrato que ha hecho surgir el título-valor, no tienen eficacia contra el legítimo tenedor de buena fe (Vivante, 1982.).

Para explicar lo dicho, sigamos con el ejemplo: Digamos que el inmueble que le vendió $A$ a $B$ adolece de vicios redhibitorios. Si al vencimiento de la letra de cambio $C$ inicia la acción ejecutiva en contra de $A$, por ser aquel $(C)$ legítimo tenedor exento de culpa, este (A) no le podrá proponer con éxito la excepción de vicios redhibitorios a C. Justamente ahí radica la protección que le brinda la ley a $C$, es decir, no tiene que preocuparse de los inconvenientes que tuvieron $A$ y $B$ en relación con el contrato que dio origen al título-valor, pues se considera que tiene un derecho nuevo de aquí en adelante, desprovisto de todos aquellos problemas sobre negocios jurídicos anteriores que estuviesen relacionados con el negocio. Si no fuera así, desincentivaría la circulación de los títulos-valores, pues casi que obligaría al nuevo tenedor a averiguar por cada negocio entramado sobre el título-valor. Sin embargo, el deudor (para el caso A) conserva contra $B$, las acciones ordinarias por el incumplimiento del contrato.

Los derechos autónomos no se predican interpartes, el título debe circular para que el primer endosatario los adquiera. Tampoco adquieren derechos autónomos aquellos tenedores que no estén de buena fe exenta de culpa ${ }^{7}$. De similar forma, nunca adquieren derechos autónomos aquellas personas que reciban en propiedad títulos-valores por una forma diferente al endoso, tal cual lo vimos anteriormente. Esto último quiere decir, que se hace vulnerable a todos aquellos escoyos que pudo tener el documento en relación con negocios que se entramaron en él en el pasado.

\section{Incorporación}

Una buena forma de entender esta característica de los títulos-valores, es la analogía que hacíamos al inicio en relación con el dinero y en particular con los billetes. La incorporación hace relación a la unión entre dos cosas: el título y el valor. El título viene siendo el componente físico (o virtual) que sirve como recipiente al derecho. En otras palabras, existe una posesión del derecho sobre el documento que los funde en una relación jurídica inescindible, afecto a unos intereses económicos específicos. En este mismo sentido, el artículo 619 del C.co. hace relación a que el documento es necesario para ejercer el derecho que en él se incorpora (Con. 621 y 624 C.co)

De la existencia del derecho, depende la existencia del título. El título es lo principal y el derecho lo accesorio. Es por esto, que cuando se van a cobrar intereses se debe exhibir el título, igualmente si se va a hacer efectivo el título-valor. En este último caso si se paga la totalidad, se debe entregar el instrumento a quien pague, lo que por lógica evitaría eventuales segundos cobros. Y si se hace un pago parcial, debe anotarse en el documento, lo que implica que el derecho incorporado se modifique. En otro tipo de derechos, estos últimos son los principales y los documentos son los accesorios. Así por ejemplo en un contrato de arrendamiento por escrito, el arrendador no tendrá que

7. Fundamento de las excepciones a la regla en materia de autonomía: Art. 784 C.co núm. 12: "Las derivadas del negocio jurídico que dio origen a la creación o transferencia del título, contra el demandante que haya sido parte en el respectivo negocio o contra cualquier otro demandante que no sea tenedor de buena fe exenta de culpa". 
estar exhibiendo el documento contentivo del contrato cada vez que cobre el canon o renta al arrendatario, o si se le perdiera el contrato no podríamos decir, que ya no tiene derecho a recibir el canon o solicitar el bien. Como la anotábamos, en este caso el derecho a recibir el arrendamiento, es independiente de que exista un documento o no, en cambio en materia de títulos-valores, por aquello de la incorporación, si se pierde destruye o extravía, no puede exigir el derecho, hasta tanto no tenga el documento, o lo reconstruya (Garrigues, 1987).

Como lo anotábamos, las obligaciones que incorpora un título-valor, tienen causa en un negocio jurídico, por tanto, en principio, si se pretende ejercer el derecho que había nacido de un contrato, pero que hoy se materializó en un título-valor, el derecho se exige a partir de la ejecución del título-valor y no del contrato ${ }^{8}$. Es lo que en la doctrina se ha llamado la convención ejecutiva, pues la obligación que se sustentaba en el contrato, transmigra con todo su contenido al título-valor y por ende, se rige por las reglas que uniforman estos instrumentos (Rengifo \& Nieto, 2010).

\section{Aspectos fundamentales especiales}

Con el nombre de este capítulo, se quiere hacer referencia a otros aspectos fundamentales y de diaria discusión en materia de títulos-valores, que, aunque en estricto sentido no hacen necesariamente parte de la teoría general, en sentido amplio si lo son, por tener una extensa relación y aplicación en consonancia con la parte general. No se nos olvide que, al fin y al cabo, lo que más interesa en este escrito, es tener un panorama general de los títulos-valores con la finalidad de introducir a un estudio más vasto, o recordar o ampliar conceptos sobre la materia.

\section{Todo título-valor es un título ejecutivo, pero no todo título ejecutivo es un título-valor}

Un título-valor es una especie de título ejecutivo, de ahí que el título ejecutivo es el género que aglutina los diferentes documentos que cumplen con los elementos formales que describe el artículo 422 del Código General del Proceso (en adelante C.G.P), y que en esencia hemos conocido como aquellos documentos que contienen obligaciones claras, expresas y exigibles que provengan del deudor y constituyan plena prueba contra él. De la lectura del dicho artículo, de inmediato se notará que no existe un listado taxativo o una tarifa legal para comprender cuales se consideran títulos ejecutivos. Bastará que el documento sea contentivo de los elementos que exige la mencionada norma para que sea susceptible de encausar mediante un proceso ejecutivo. Con todo, podemos recordar los más tradicionales: las sentencias judiciales, los laudos arbitrales, las actas de acuerdo conciliatorio y por supuesto, los títulos-valores.

Antes de proseguir, vale la pena recordar porqué se utiliza el proceso ejecutivo para los títulos ejecutivos. En principio, se considera que cuando se presenta ante el juez un título ejecutivo, justamente se presenta un documento que contiene una obligación que es tan serena, que no amerita una discusión de fondo, por lo que se supone, el juez sencillamente debe hacerla cumplir de conformidad a lo que el documento dice. Por eso, al contrario, en los procesos de conocimiento como por ejemplo los verbales, al no existir un documento que dé cuenta de la certeza de una obligación o de una determinada relación jurídica, amerita un procedimiento donde a partir del debate probatorio, se logre dar certeza y firmeza a una relación jurídica incierta

8. Salvo que no sea posible cobrar el derecho incorporado en el título-valor. En este evento, se entiende que la condición resolutoria de pago es fallida y, por ende, se puede hacer uso de la acción causal contemplada en el artículo 882 inc. 2 C.co. En otras palabras, si el deudor no paga, el acreedor podrá: ejecutar la obligación por intermedio del título-valor, o iniciar un proceso de conocimiento buscando la resolución o terminación del contrato, lo que vendría siendo la acción causal. La acción causal está supeditada a los títulos-valores de contenido crediticio (letras, pagarés, facturas, etc). 
mediante una sentencia judicial. No en vano, el primer acto procesal en un proceso de conocimiento es el auto admisorio de la demanda y en un proceso ejecutivo se libra mandamiento de pago. En este último caso el juez al hace una revisión formal del documento y si encuentra que cumple con los requisitos del artículo 422 en comento, presume que es cierta la obligación que contiene el documento, por lo que no le queda más que requerir al deudor para que pague o cumpla la obligación en un determinado tiempo. Pero obvio es decir, no necesariamente el hecho de existir un documento que contenga esas características lleve al acreedor hacia una segura ejecución final, no, el demandado también puede proponer defensas en su favor, ya sea desconociendo aspectos formales del documento como podría ser la falta de claridad o exigibilidad, o cuestiones de fondo como el pago o cumplimiento de la obligación, no en vano, en el mismo mandamiento de pago también el juez concede un término para que se defienda si a bien lo tiene. Por ello, cuando el deudor propone excepciones de mérito o fondo, el proceso toma la apariencia de un proceso de conocimiento, sin dejar de ser ejecutivo.

En fin, lo dicho hasta ahora tiene una finalidad, y es que, aunque el título-valor debe comportarse como un verdadero título ejecutivo procesalmente hablando, lo cierto es que, de manera sustancial puede encontrar grandes diferencias con sus homólogos. De hecho, un error académico en la práctica es confundir la palabra títulos-valores con títulos ejecutivos, pues se repite, son homólogos mas no sinónimos, no se puede confundir la especie con el mismo género. Quizás la confusión se deba a la similitud semántica del inicio de cada descripción: título; como también, se tratan de los títulos ejecutivos de mayor usanza en la práctica (Bejarano, 2018).

Pero de forma más concreta podemos encontrar las siguientes distinciones:

- En relación con el documento que incorpora el derecho: La definición de documento es más amplia de lo que pudiera creerse. Quizás estaríamos tentados a decir que documento, es un documento escrito, pero no, resulta que de conformidad con el artículo 243 del C.G.P un documento es "...en general, todo objeto mueble que tenga carácter representativo o declarativo..." por tanto, dentro de esta definición caben documentos tales como: grabaciones, fotografías, entre otras. En materia de títulos-valores solo pueden utilizarse aquellos documentos que se permitan firmar, como serían los físicos y eventualmente los electrónicos 9 , pues el fundamento de la obligación cambiaria es la firma tal como lo prescribe el artículo 626 del C.co. Así, por ejemplo, si una persona mediante una grabación en video o de audio, se compromete a pagar una suma de dinero aduciendo que lo hace como si fuera un pagaré, pues en realidad no sería tal, pues no está firmando, pero sin duda, podríamos estar hablando de un título ejecutivo común, de cumplir con sus requisitos.

- En relación con las prestaciones que incorpora el documento: Un título ejecutivo puede contener prestaciones de dar, hacer o no hacer. Pero un título-valor suele incorporar comúnmente obligaciones de dar como sería pagar una suma de dinero, o de hacer como en una acción de una sociedad de capital que obliga al ente societario a permitir participar al socio en las decisiones políticas de la sociedad. Lo que no incorpora un título-valor, son prestaciones de no hacer, riñen con su naturaleza, es inimaginable la exigencia de una abstención mediante un título-valor.

9. La ley 529 de 1999 permite la firma electrónica como un equivalente funcional, por tanto, es posible la suscripción de un documento, inclusive títulos-valores, que cumplan con los requisitos de ley. 
- En relación al condicionamiento de la obligación: Por regla general, las obligaciones contenidas en títulos ejecutivos, pueden someterse a condición, esto es, el nacimiento o la extinción de dichas obligaciones, puede depender de un hecho futuro e incierto. Las obligaciones en los títulos-valores no pueden someterse a condición. La condición repugna al derecho de los títulos-valores, pues resta seriedad y certeza a las obligaciones que puedan incorporarse en dichos documentos. El mismo C.co. dependiendo el caso, les resta efectos a las condiciones, de forma diferente. Por ejemplo, un endoso condicionado (art. 655 C.co) se entiende por no puesto, es decir, si se condiciona un endoso, este tiene plenos efectos, mas no la condición, 0 , en el caso de la aceptación condicionada de una letra de cambio, la ley le resta efectos no solo a la condición, sino a la misma aceptación, en otras palabras, asume que el girado no quiso obligarse (art. 687 C.co).

- En relación con su contenido: Toda obligación incorporada se presume de pleno derecho mercantil. Es decir, no importa la naturaleza de la relación jurídica que le dio origen, por ejemplo, laboral o administrativa, pues en lo sucesivo, la obligación trasmigra a un bien eminentemente mercantil ${ }^{10}$, por ende, seguirá su régimen. Lo dicho tiene especial trascendencia en materia procesal y específicamente en la competencia por el factor objetivo en su modalidad de naturaleza del asunto. En efecto, si un patrono se compromete a pagar a su empleado determinadas prestaciones sociales adeudadas por intermedio de un título-valor, y en similar sentido un ente de carácter público promete pagar a un contratista una suma de dinero en un instrumento de igual naturaleza, la competencia para iniciar el proceso ejecutivo no será el juez laboral y el juez administrativo respectivamente (como podría creerse), sino que será la jurisdicción civil. Así lo tiene sentado la jurisprudencia de la Corte Suprema de Justicia en materia laboral ${ }^{11}$ y el Consejo de Estado en materia contenciosa administrativa ${ }^{12}$.

- En relación con la originalidad del documento: De forma excepcional, se ha aceptado copias auténticas como títulos-ejecutivos, tales como serían la primera copia de un acta de acuerdo (art. 1 parágrafo 1 ley 640 de 2001) - la primera copia de una escritura pública de la que puedan exigirse obligaciones (art. 80 Decreto-ley 960 de 1970). Pero, en materia de títulos-valores, una copia, aunque sea auténtica, no tiene el carácter de título ejecutivo, pues el derecho incorporado solo reside en un único documento, recordemos que entre el título y el valor existe una relación inseparable, producto de la incorporación; pero además se torna indispensable la exigencia del original, por razones de seguridad jurídica ${ }^{13}$. Inclusive, aunque el mismo CGP de forma general le da el mismo valor probatorio de las copias que la original de inmediato reconoce que la excepción se da cuando una norma haga necesaria la presentación del original, tal como ocurre con los títulos-valores; según vimos, el artículo 640 del C.co indica que el ejercicio del derecho requiere la exhibición de este.

Con todo, pueden existir algún caso donde una fotocopia pueda ser útil. Por ejemplo, se puede pensar en la pérdida de un título-valor, pero su dueño

10. Ver artículo 20 núm. 6 C.co.

11. Auto, Sala Plena, Corte Suprema de Justicia (marzo 23 de 2017, M.P. Patricia Salazar Cuéllar).

12. El Consejo de Estado ha sostenido dos posiciones; la primera, en virtud de la cual sustentaba que cuando el proceso ejecutivo provenga un título-valor, as tenga por causa un contrato estatal siempre la jurisdicción competente es la ordinaria (Sección Tercera en el auto del 9 de marzo de 2000); la segunda, revisaba la anterior para sostener que solo conocería la ordinaria si el título-valor circulaba de lo contrario conocía la contenciosa (Febrero 21 de 2002 Sección Tercera C.P. Alier Eduardo Hernández Henríquez). En sentencia más reciente del Consejo de Estado, se retornó a la primera posición (mayo 14 de 2014 C.P. Enrique Gil Botero). 13. Sección tercera Consejo de Estado, sentencia mayo 14 de 2014 (...) 
tiene una fotocopia, la misma puede servir en un proceso de cancelación y reposición de título-valor como prueba documental, lo que permitirá identificar y generar precisión al reponer el nuevo título, teniendo en cuenta las características del extraviado ${ }^{14}$.

- En relación con la transferencia y circulación de los derechos: Un derecho de crédito, es un bien que está dentro del patrimonio de una persona y, por ende, puede ser susceptible de cualquier negocio jurídico como lo sería por ejemplo una venta. Imaginemos que, mediante acta de acuerdo, A se compromete a pagar una suma de dinero a $B$, lo que quiere decir que $B$ tiene un derecho de crédito a su favor y en contra de $A$. Si $B$ quiere ceder dicho crédito, deberá realizarlo de conformidad a las normas del derecho civil, más concretamente, a partir de la cesión de créditos (artículos 1959 y sgts C.C.), lo que se materializaría a partir de una carta de traspaso. En cambio, cuando se trata de un título-valor y se va negociar de forma regular, es decir, mediante endoso, las normas que entran a regir tal transacción son las del Código de Comercio sobre la materia. Y las diferencias entre los efectos en relación con la transferencia y circulación, son abismales: La transferencia de derechos representados en documentos que no son títulos-valores, no generan derechos autónomos, pues sus efectos se rigen por la cesión de créditos, por tanto, las virtudes como las vicisitudes acompañan al cesionario en su derecho. Por regla general el cedente no se hace responsable de la solvencia del cedido, mientras que, por regla general, quien endosa en materia de títulos-valores, se responsabiliza frente al endosatario de la solvencia del deudor. En la cesión de derechos representados en documentos que no son títulos-valores, debe cuanto menos notificarse al cedido para que este quede vinculado, en materia de títulos-valores, no es necesario notificar al deudor, el solo endoso perfecciona la obligación del deudor, bastará con que el acreedor se presenta el día del vencimiento y exija la obligación de inmediato.

\section{Particularidades sobre la firma}

La firma en general tiene como función: identificar a una persona, y materializar en la realidad una manifestación de la voluntad. Esas mismas funciones cumple la firma en un título-valor, pero de manera particular el artículo 621 del C.co. plantea que la firma es un elemento de la esencia en los títulos-valores, pues es necesaria para su existencia, para luego decir que la misma se cierne como fundamento de la obligación cambiaria (art. 625 C.co).

Lo anterior quiere decir, que la firma en materia de títulos-valores tiene una doble connotación: a) Crear el título-valor: no es posible crear un título-valor sin que haya una firma. b) Crear obligaciones: Quien firma generalmente lo hace con la finalidad de obligarse, pero no siempre quien firma lo hace con esa intención, o en ocasiones, aunque lo haga con esa intención, su firma no lo obliga. En el caso de quien firma sin la intención de obligarse, podríamos pensar en el llamado "endoso sin mi responsabilidad" (art. 657 C.co), como su nombre lo indica, el endosante transfiere el derecho incorporado en el título y legitima a su nuevo tenedor, pero sin quedar vinculado en la relación cambiaria, siendo lo normal que el endosante se obliga para con el endosatario a responder por el pago del título-valor. En razón de quien firma con la intención de obligarse, pero no se obliga, podemos pensar en un menor de edad que suscribe un título-valor con el propósito de obligarse, más dicha firma no

14. Para conocer su procedimiento, ver artículos 802 y siguientes del C.co. y 398 C.G.P. 
lo obliga por no tener la capacidad de ejercicio; si fuera demandado puede proponer la excepción de incapacidad al momento de suscribir el título (art. 784 núm. 2 C.co).

Por otro lado, el capítulo sobre títulos-valores en el Código de Comercio no contiene una definición de lo que debe entenderse por firma, por lo que se aplica en su totalidad la contenida en el artículo 826 del C.co. la que a su tenor indica: "Por firma se entiende la expresión del nombre del suscriptor o de alguno de los elementos que la integren o de un signo o símbolo empleado como medio de identificación personal." Como podemos observar, la regla general es que la firma debe ser autógrafa y puede estar compuesta por algún elemento del nombre de la persona, pero nada se opone a que, en vez de su nombre, plasme en el documento cualquier signo o símbolo bajo la condición que cuando use tal signo lo haga no solo con la intención de identificarse con él, sino también en materia de títulos-valores, lo haga con la intención de obligarse. Mas adelante el artículo 827 del C.co., de forma excepcional permite la firma mecánica (como la de un sello), siempre y cuando tengan como sustento una norma o una costumbre que lo avalen ${ }^{15}$ y exista una voluntad inequívoca de obligarse mediante ella.

Ahora, en razón a la forma que debe contener la firma manuscrita, la posibilidad es amplia, inclusive un dibujo podría tener la calidad de tal, bastará con que exista la certeza de que es realizada por el deudor. La Corte de Suprema de Justicia en sentencia de 15 de diciembre de 2015 M.P. Julio César Valencia Copete, dijo en relación con la forma de la firma:

...para nada interesa, entonces, la forma como finalmente resulte plasmada, vale decir, si es o no legible, si su conformación sugiere una presentación agradable, si describe o no los nombres y apellidos de quien la realiza, si se ciñe a las reglas de ortografía, y menos las condiciones particulares del ejecutor, entre ellas, si es letrado, pues basta con la certeza de que los signos impuestos fueron de su autoría" (Valencia \& Garcés, 2008).

Una pregunta: ¿Es posible obligarse en un título-valor sin firmar? Como se indicó, por regla general, la firma es el fundamento de la obligación cambiaria, pero, con el devenir de la factura de venta (la reforma más reciente al régimen de los títulos-valores) ${ }^{16}$ al parecer es posible que alguien se obligue sin firmar, mediante la llamada aceptación tácita.

Antes que nada, la factura de venta es un título-valor de contenido crediticio (incorpora el derecho a reclamar dinero) mediante el cual, un comerciante que vende mercancías o presta servicios y en particular a crédito, garantiza que el beneficiario de bienes o servicios le pague el precio a partir de la garantía que le propicia dicho título-valor ${ }^{17}$. De todos los días, los consumidores de bienes y servicios reciben dichas prestaciones y con posterioridad el comerciante envía las facturas de venta donde relacionan los bienes vendidos o los servicios prestados, a los domicilios de los consumidores. Una vez presentada la factura en el domicilio del consumidor, este puede: aceptar expresamente la factura de venta (firmándolo el mismo u otra persona mediante poder escrito ${ }^{18}$ ) en el cuerpo de la factura o en documento separado (art. 773 inc. 2), aceptarla mediante una firma por representación presunta, o aceptarla tácitamente.

15. En relación con una norma que avale una firma mecánica, el ejemplo lo encontramos en el artículo 754 inc. final en relación con los bonos. Los bonos son títulos-valores que pueden suscribir las sociedades de capital (por ejemplo, una sociedad anónima) como una forma de capitalización. Explicando de forma sencilla, la sociedad adquiere dinero del público y se compromete a pagarlo mediante la suscripción de dichos bonos. Piénsese en una sociedad que emite miles de bonos y los que deben ser firmados por el representante legal de la sociedad mercantil, no sería práctico utilizar aquí su firma manuscrita. En relación con la forma mecánica avalada por la costumbre, por la misma razón que en el caso anterior, se ha aceptado la firma a computador de cheques para pagar los salarios a empleados en empresas grandes (Calle, 2006).

16. Arts. 774 y siguientes C.co. modificados por la ley 1231 de 2008

17. Incorporar el pago de los bienes o servicios mediante una factura de venta, permite al comerciante además de la garantía personal, cumplir con las obligaciones prescritas en el Estatuto Tributario (art.617).

18. Para firmar un título-valor por otro, el poder debe ser estar por escrito (art.640 inc. 2) 
Frente a esto último, es común en grandes y medianas empresas, que quien recibe las facturas no propiamente es el gerente o dueño del establecimiento de comercio, sino personal a su cargo como por ejemplo, un bodeguero, un recepcionista, por ello, aparece la posibilidad de aceptar las facturas por medio de una firma realizada por un dependiente del beneficiario de los bienes y servicios, caso en el cuál su aceptación se dará por una representación presunta, o recibiéndola el dependiente sin firmar (o inclusive el mismo beneficiario) se genere una aceptación tácita ${ }^{19}$.

En ocasión de la firma por representación presunta, encontramos un dependiente del beneficiario que recibe las facturas, las firma con su puño y letra (además debe imponer su fecha de recibo). En este evento, el consumidor se considera aceptante y no podrá alegar falta de representación o indebida representación por parte de quien recibió y firmó la factura, salvo que deje dicho acto sin efectos, haciéndolo conocer al vendedor mediante escrito, o devolviendo la factura junto con sus documentos de despacho, dentro de los tres días siguientes hábiles a su recepción.

En razón de la aceptación tácita (que es la que más nos interesa en el tema en cuestión), el dependiente o el mismo consumidor reciben la factura, no la firman, pero en manos del vendedor no reclaman contra su contenido dentro de los tres días siguientes a su recepción, por lo que la factura se comprenderá irrevocablemente aceptada (C.co. art. 773 inc. 3). Veamos con un ejemplo: A compra a $B$ unas mercancías a plazo. Con las mercancías, $B$ envía la factura de venta junto con una copia de esta. $C$, dependiente de $A$ (o incluso el mismo A), recibe la factura y sin firmar, pone un sello de recibo en la factura original, quedándose tan solo con la copia. Si pasan tres días, y $A$ no reclama a $B$ el contenido de la factura, mediante escrito o devolución de la factura con sus documentos de despacho, la factura se considera irrevocablemente aceptada ${ }^{20}$.

En el pasado, Tribunales Superiores, se negaban a librar mandamientos de pago cuando tan solo se presenciaba un sello de recibo y no una firma del comprador o dependiente, pero la Corte Suprema de Justicia en sentencia de tutela del 20 de octubre de 2016 (M.P. Álvaro Fernando García Restrepo), revaloró dicha tesis, dejando clara la aplicación de la aceptación tácita. El caso fue el siguiente: Un vendedor presentó una factura de venta a su comprador y en la misma fue impuesta por este último, la siguiente leyenda: "Recibido para su estudio, no implica aceptación". En primera y segunda instancia, los jueces civiles consideraron que la factura no se consideraba aceptada y por ende le restaron efectos de título ejecutivo.

Sin otro recurso, el demandante en aquel proceso, instauró acción de tutela contra la sentencia del Tribunal, alegando una vía de hecho por error sustancial, lo que fue acogido por la Corte en los siguientes términos:

...contrario a lo afirmado por la autoridad judicial convocada, la sola imposición en las carátulas de las facturas objeto de cobro, de sello con la leyenda -RECIBO PARA SU ESTUDIO NO IMPLICA ACEPTACIÓN-, no se contrae a la mera recepción del título, pues lo cierto es que como se ha dicho jurisprudencialmente, ese acto como tal conduce a la aceptación de la factura, sin que tenga incidencia alguna el estudio posterior que el beneficiario o comprador de los servicios o mercancías, pretenda realizar.

19. La aceptación tácita es aquella, que sin ser expresa, da entender inequívocamente, que quiere obligarse. En materia de facturas de venta, la aceptación tácita la va a marcar, no reclamar contra el contenido del documento, dentro de los tres días siguientes a su recibo tal como lo veremos en un momento.

20. Vale decir, que debe existir certeza en la factura de la fecha de recibo, pues es garantía para el deudor para saber desde cuando se cuentan los tres días que tiene para hacer su reclamo. 
En un caso de similares contornos al sometido a examen, la Sala sostuvo lo siguiente:

Significa lo anterior que si la ejecutada, como lo predicó el mismo juez de conocimiento, recibió las facturas cuyo cobro se pretendió y las dejó para el trámite respectivo, sin que las hubiese devuelto, ni objetado su contenido en el término estipulado en la norma precedente, ello comporta la aceptación irrevocable de que trata el precepto en cuestión, no habiendo lugar a que se predicara, como lo hizo el funcionario querellado, que en relación con ellas, no se cumplía el requisito que se echó de menos.

En síntesis, recibir una factura de venta y no firmarla, igual puede generar responsabilidad cambiaria de conformidad al artículo 623 del C.co., es decir, se entiende obligado como si hubiese firmado. En este evento, la ley crea en una conducta omisiva: recibir y no reclamar, un asentimiento tácito que obliga, y de contera, lo convalida como sustituto del cimiento general de la obligación contemplado en el artículo 625 del C.co.

\section{Elementos naturales y accidentales de los títulos-valores}

Los títulos-valores como portadores de actos jurídicos, pueden contener elementos esenciales, naturales y accidentales ${ }^{21}$. Elementos esenciales a todo título-valor son: la firma y la mención del derecho incorporado, sin ellos, el documento no tendrían efectos, serían inexistentes (art.620 C.co.), de tal manera que no podrá existir un título-valor, que como mínimo no contenga real o potencialmente ${ }^{22}$ la especificación del derecho que se quiere exigir (como dinero, mercancías, derechos políticos) y una firma. Naturales serían aquellos que, si el creador del título los omite, la ley los va a presumir tal como sucede con el lugar y la fecha de creación. Accidentales serían aquellos que, sin ser esenciales y naturales, se agregan por el creador, tales como los intereses de plazo o cláusulas aceleratorias de pago.

Los elementos naturales de los títulos-valores se encuentran contemplados en el artículo 621 del Código Comercio con relación al lugar de pago, el lugar creación y la fecha de creación. En correspondencia con el primero, sino se dice el lugar de creación, se entenderá que será el lugar de entrega real y material que le hace el creador-deudor a su acreedor, en relación con el segundo, sino se dice la fecha de creación se entenderá que será el mismo día en que el creador-deudor entregue real y materialmente el título, y en relación al tercero, si no se dice el lugar de pago, será el del domicilio del creador, que normalmente coincide con el del deudor ${ }^{23}$. Los elementos naturales van a tener relevancia en el título y en su exigibilidad de la siguiente manera:

Es muy normal introducir en el texto del título-valor, el lugar de pago de la obligación que no siempre coincide con el domicilio del deudor, lo que puede incidir en materia de competencia territorial si se quiere iniciar un proceso ejecutivo. Ante este supuesto, es decir, cuando el domicilio de pago y el del deudor son diferentes y ante el incumplimiento de la obligación ¿cuál es el juez competente territorialmente? El C.G.P., artículo 28 expresa:

21. Aunque un título-valor no es propiamente un contrato, pues se trata de un documento que contiene declaraciones unilaterales de voluntad de quienes se obligan, es perfectamente aplicable en cuanto a sus elementos, lo contemplado en el artículo 1501 del Código Civil: "Se distinguen en cada contrato las cosas que son de su esencia, las que son de su naturaleza, y las puramente accidentales. Son de la esencia de un contrato aquellas cosas sin las cuales, o no produce efecto alguno, o degeneran en otro contrato diferente; son de la naturaleza de un contrato las que, no siendo esenciales en él, se entienden pertenecerle, sin necesidad de una cláusula especial; y son accidentales a un contrato aquellas que ni esencial ni naturalmente le pertenecen, y que se le agregan por medio de cláusulas especiales.

22. Veremos que es posible dejar en blanco la mención del derecho incorporado, pero con las instrucciones para completarlo, antes de su cobro. 23. Como se puede intuir, lo que primero va a primar, es lo que rubrique el creador. Así, por ejemplo, aunque la fecha material de elaboración sea el primero de enero de 2018, pero se impone en el documento el 1 de febrero de 2018 como fecha de creación, será esta última la que se entiende por fecha real para los efectos del título. 
La competencia territorial se sujeta a las siguientes reglas:

1. En los procesos contenciosos, salvo disposición legal en contrario, es competente el juez del domicilio del demandado. Si son varios los demandados o el demandado tiene varios domicilios, el de cualquiera de ellos a elección del demandante. Cuando el demandado carezca de domicilio en el país, será competente el juez de su residencia. Cuando tampoco tenga residencia en el país o esta se desconozca, será competente el juez del domicilio o de la residencia del demandante.

Éste primer numeral, conlleva la regla general de competencia. Es decir, por regla general se debe demandar, en el domicilio del demandado y especialmente cuando se trate de procesos contenciosos, como es el caso también, en los que se ejecutan los títulos-valores. De ahí en adelante, la ley procesal empieza a esbozar otro tipo de situaciones para generar competencia territorial, las que pueden ser concurrentes con la anterior regla general, o sea, puede escogerse si es del caso, un juez competente territorial u otro. Por esta razón, cuando el título-valor (que es a la vez una especie de título ejecutivo) tiene un lugar de pago voluntario establecido por el creador, también será a la vez un determinador de factor de competencia territorial en caso de Litis. Manifiesta el numeral 3 del C.G.P:

3. En los procesos originados en un negocio jurídico o que involucren títulos ejecutivos es también competente el juez del lugar de cumplimiento de cualquiera de las obligaciones...

Expliquemos con un ejemplo: $A$, domiciliado en Medellín, suscribe un pagaré a la orden de $B$, por la suma de 200.000.000 de pesos, los que serán pagados en la ciudad de Bogotá (que sería el lugar de cumplimiento de la obligación), el día 22 de agosto de 2010. Si llegado el día de la exigibilidad, $A$ incumple, $B$ podrá iniciar un proceso ejecutivo en contra de $A$ y para ello puede hacerlo ante los siguientes jueces: Ante el juez civil de Medellín, por ser este el domicilio de $A$, o ante el juez civil de Bogotá, por haber sido este el lugar pactado para el pago de la obligación.

En consonancia con el lugar de creación es importante sobre todo en materia de cheques, porque de conformidad con el artículo 718 del C.co. la presentación oportuna para el pago ante un banco va a depender de la ubicación del banco o sucursal donde se encuentra abierta la cuenta corriente bancaria, con respecto al lugar de giro o creación del cheque. Si una persona abre una cuenta corriente bancaria en un banco de Medellín y gira o crea el cheque en Medellín, el beneficiario del cheque tendrá 15 días para hacer la presentación oportuna para el pago ante un banco, pero si resulta que el cheque es girado o creado en Bogotá, el beneficiario tendrá un mes para su presentación ${ }^{24}$.

La fecha de creación tiene incidencia en varios aspectos tales como: Títulos-valores con forma de vencimiento a la vista, la aceptación de las facturas de venta y los intereses de plazo. La forma de vencimiento "a la vista" es una manera de hacer exigible un título-valor, mediante la exhibición material que le hace el acreedor al deudor del título; normalmente, el acreedor debe realizar dicha exhibición dentro de año que siga a la fecha de creación (art. 692 C.co). La incidencia de la fecha de creación 24. Vale aclarar, que el cheque puede presentarse ante cualquier sucursal o agencia del país (inclusive a un banco diferente mediante la modalidad de consignación), pues la ubicación del banco de procedencia con respecto al lugar de giro solo tiene incidencia en relación con los tiempos de presentación oportuna, por ello, en el caso del cheque creado en Bogotá, se puede presentar para su pago en un banco en Medellín sin que varíe el término de un mes para su presentación. 
en la factura de venta se da en la denominada aceptación tácita (tal cual la vimos anteriormente), pues el término de 3 días para declarar dicha aceptación o en su caso, para rechazarla, se cuentan desde la fecha de creación. Los intereses de plazo o también llamados remuneratorios, son aquellos que se causan desde la fecha de creación hasta antes de que se haga exigible la obligación y tienen como finalidad compensar la perdida del valor del dinero por el paso del tiempo.

A propósito de los intereses y con el ánimo de redondear el tema, los de plazo solo podrán cobrarse en los títulos-valores si se pactan (elemento accidental) por lo que no se presumen, mientras que los intereses de mora (que se cobran por el retardo en el pago) por el contrario, sino se pactan, se presumen (elemento natural). Lo inmediatamente dicho tiene sustento en el artículo 884 del C.co ${ }^{25}$ el que dice que:

Cuando en los negocios mercantiles haya de pagarse réditos de un capital, sin que se especifique por convenio el interés, éste será el bancario corriente; si las partes no han estipulado el interés moratorio, será equivalente a una y media veces del bancario corriente... (subrayas y cursiva fuera de texto).

La parte subrayada inicia su redacción bajo el entendido que las partes pactaron el interés de plazo, pero no el monto, por tanto, lo que hace la norma es suplir este vacío diciendo que será el bancario corriente. La parte en cursiva hace referencia a los intereses de mora, y su regulación va más allá, pues suple el silencio frente a su pacto, como frente a su monto ${ }^{26}$. Finalmente se pregunta: ¿si se pactan intereses de plazo verbalmente, pero no quedan en el título-valor? No se pueden cobrar, por no estar literalizados en el título y, por tanto, al momento de la ejecución no constituiría una obligación clara y expresa al no estar en el documento.

\section{Títulos-valores en blanco y con espacios en blanco}

Existe la posibilidad de dejar espacios en blanco en un título-valor siempre y cuando existan instrucciones de cómo llenarlos, por existir la voluntad del creador y para cumplir fines económicos específicos; así lo regula el artículo 622 del C.co. Lo que se deja en blanco son alguno o algunos de los requisitos esenciales generales como el derecho incorporado y fecha de vencimiento (que la ley no suple ante su ausencia), aunque también se suelen dar instrucciones de manera segundaria de cómo han de completarse elementos generales no esenciales, tales como la fecha de creación, los intereses de plazo y mora, etc. El creador del título-valor es quien da las instrucciones de cómo llenarlo y por ello es indispensable mínimo su firma, es decir la firma del creador es el único requisito esencial no se puede dejar en blanco. Se debe hacer hincapié que deben dejarse instrucciones de como deben llenarse dichos espacios en blanco las que pueden ser verbales o escritas. En ese sentido, dijo la Corte Constitucional en sentencia T-968 de 2011 (M.P. Gabriel Eduardo Mendoza Martelo):

...(i) la carta de instrucciones no es imprescindible, ya que puede haber instrucciones verbales, o posteriores al acto de creación del título o, incluso implícitas, y, (ii) la ausencia de instrucciones o la discrepancia entre éstas y la manera como se llenó el título valor, no necesariamente le quitan mérito ejecutivo al mismo, sino que impone la necesidad de adecuarlo a lo que efectivamente las partes acordaron.

25. Además, el artículo 783 del C.co., indica qué se puede reclamar mediante la acción cambiaria, donde en relación con los intereses, solo enlista los intereses de mora, mas no los de plazo, por lo que debe entenderse, que estos últimos se pueden reclamar, solo si se explicitan en el título-valor.

26. En lo que tiene que ver con los montos en los intereses y especialmente las consecuencias de su cobro excesivo, se recomienda la obra del profesor Enrique Díaz Ramírez (2014) 
Para hacernos una idea de su finalidad económica, podemos referenciar la usanza de las entidades financieras de esta forma de títulos-valores. Cuando una persona solicita un crédito, previo a su desembolso, deberá firmar un título-valor con espacios en blanco, allí normalmente se dejan espacios sin llenar como el valor a pagar (derecho incorporado) la fecha de exigibilidad y los intereses. Adicionalmente, esta misma persona debe firmar una carta de instrucciones donde indica de qué forma pueden llenarse esos espacios en blanco. Supongamos que un tiempo después el deudor incumple con el plan de pagos negociado con el banco y precisamente este el hecho o condición que permitirá al banco llenar los espacios en blanco, por ejemplo, podrá rubricar el saldo insoluto, los intereses y la fecha de exigibilidad. En relación con la fecha de exigibilidad debe acotarse, que mientras no se imponga en el título-valor, no corren los términos de prescripción, es por eso que, en los créditos a largo plazo, aunque se haya suscrito el título-valor hace 5 o más años, mientras el titular del título y conforme la instrucción no la haya completado, no podrá alegarse prescripción, pues para que pueda correr, es necesario que exista una fecha de exigibilidad, desde la cual puedan contarse. Esto tiene que ver mucho con la finalidad económica, porque permite apalancar créditos a largo plazo por intermedio de títulos-valores, sin preocuparse por los términos de prescripción.

Ahora, de la lectura del artículo 622 del C.co. se puede deducir que es diferente un título-valor con espacios en blanco (621 C.Co. inc.1) de una firma puesta sobre un papel en blanco (622 C.Co. inc.2). En el primero, existen elementos parciales o algunos trazos de un título-valor (o elementos indicativos de una posible obligación cambiaria) tales como: denominación del título, firma del suscriptor, lugar de creación, etc; pero que se dejan otros en blanco, tales como: derecho incorporado (suma de dinero a pagar) fecha de vencimiento, etc., piénsese por ejemplo en el caso de un formato comercial de un pagaré dónde se llenan unos espacios y otros se dejan en blanco. En el segundo, existe un papel absolutamente en blanco con una firma, sin que se contenga en él espacios específicos para posteriormente llenarlos.

La anterior aclaración importa, ya que en el caso de la firma en documento absolutamente en blanco, la exigencia de las instrucciones y su correspondiente cumplimiento es más escrupulosa que en los títulos-valores con espacios en blanco. Es así como el inc. 1 del artículo 622 del C.co., establece que cualquier legítimo tenedor podrá llenar los espacios en blanco "...conforme a las instrucciones del suscriptor..." y en el inciso 2 del mismo artículo (que habla de que una hoja en blanco con una firma) manifiesta que "...deberá ser llenado estrictamente de acuerdo con la autorización dada para ello". En esta última modalidad, se exige como requisito esencial, que las instrucciones sean estrictas, adjetivo calificativo que tiene que ver mucho con la seguridad de quien firma un papel en esas condiciones, y ello debe ser así, porque puede correr el riesgo que en el cuerpo de dicha hoja puedan redactarse condiciones obligacionales que no se habían contemplado.

Para valorar el riesgo que puede contemplar firmar una hoja en blanco, podemos contar lo que le sucedió al futbolista argentino Gabriel Omar Batistuta. Iba Batistuta caminando por las calles de Buenos Aires cuando una persona se acerca y le pide un autógrafo, a lo que el accede suscribiendo la hoja en blanco con su autógrafo "Bati". La sorpresa se la llevaría mas tarde cuando es demandado en un proceso ejecutivo con base en un pagaré elaborado con la hoja en blanco que él había autografiado. Al final Gabriel Omar Batistuta prueba que dicha firma solo se había abonado en calidad de autógrafo y no como una firma comercial, para ello logró probar que en documentos comerciales él firmaba como "Gabriel Omar Batistuta" y que "Bati" solo 
lo utilizaba al suscribir autógrafos. Entre otras excepciones propuso la mala fe, la que, probada, también prosperó27.

Para terminar, otros dos aspectos importantes: 1. Quien debe probar que un título-valor con espacios en blanco o una hoja en blanco fue llenada en contra de las instrucciones, es el creador del título, el que normalmente corresponde al deudor ${ }^{28}$. 2. Si un documento con espacios en blanco es llenado en contra de las instrucciones y luego es negociado en favor de un tercero tenedor de buena fe, este último podrá hacerlo valer íntegramente ante el deudor. Por lo anterior, es recomendable dejar por escrito las instrucciones para su llenado o cuanto menos, dejar en el pagaré la leyenda que el documento se ha suscrito con espacios en blanco y con instrucciones, así, una vez se ponga en circulación, los terceros que lo adquieran deberán probar su buena fe (León, 2017), como mínimo, indagando por las instrucciones que se dieron para completarlo.

\section{La prescripción en los títulos-valores}

En materia de títulos-valores, los términos de prescripción pueden ser variados, lo que va a depender: del tipo de obligados y del tipo de título-valor (el cheque tiene un término de prescripción diferente).

En relación con los obligados, en materia de títulos-valores, se clasifican en obligados directos y obligados de regreso. Los obligados directos son los llamados a hacer el pago y los de regreso, son responsables que el obligado directo pague. Planteemos un ejemplo: $B$, le presta una suma de dinero a $A$, por lo que suscribe un título-valor en favor de $B$. Posteriormente $B$, endosa el título $C$. Hasta aquí podemos advertir que quien tiene que realizar el pago es $A$ y el beneficiario es $C$, no obstante $B$ con su endoso le ha prometido a $C$, que, si $A$ no paga, él responderá. Esto sirve para indicar, que $A$, por ser el principal obligado, lo consideramos obligado directo y $B$ por ser responsable en caso de que A no pague, se considerará obligado de regreso. Vale decir, que una vez $C$ requiera para el pago a $A$ y este no paga, podrá exigirle la obligación de manera solidaria junto con $B$.

Ahora, es de gran relevancia advertir, que siempre que exista un obligado de regreso en un título-valor, es obligatorio antes de exigirle responsabilidad, primero debe haber presentado oportunamente el título-valor para el pago al obligado directo. Según lo indica el artículo 691 del C.co. la letra de cambio (también se incluyen otros títulos como el pagaré), deben presentarse para su pago el día de su vencimiento o dentro de los ocho días comunes siguientes. Siguiendo con el ejemplo, si $C$ no cumple con esta carga, $B$ podría liberarse de la obligación, pues solo será responsable a condición de que $C$ presente y demuestre la negativa de pago de $A$, en esos términos ${ }^{29}$. Pero si por el contrario la cumple y efectivamente $A$ no paga y desea exigir el cumplimiento no solo a él sino también a $B$, deberá regirse por los siguientes términos de prescripción: 3 años contados desde la fecha de exigibilidad para cobrar al obligado directo que para el ejemplo es A (Art. 789 C.co.) y 1 año contado desde la fecha de exigibilidad para cobrar al obligado de regreso que para el ejemplo es B (Art. 790 C.co.).

En relación con el cheque, los términos de prescripción también son diferentes. Un cheque es un título-valor mediante el cual, el cuentacorrentista tenedor de la chequera, le da a orden a un banco, para que le pague una suma de dinero a la persona que se

27. La noticia fue publicada en el diario argentino "El Clarín" el 19 de diciembre de 2012. https://www.clarin.com/policiales/estafa-pagare_0_rJiEaFhjD7l.htm 28. Puede darse el caso en el que, el creador es el mismo acreedor, como cuando una letra de cambio es girada en beneficio del mismo librador (Art. 676 C.co), en cuyo caso, es él quien debe dar y probar las instrucciones para llenar los espacios en blanco.

29. La razón por la que se libera es por la caducidad de conformidad con el artículo 784 del C.co. 
encuentre legitimada como beneficiaria. Ello quiere decir, que, por regla general, el cuentacorrentista y girador del cheque, previamente debe tener fondos en su cuenta corriente y con los que se pagarán según la suma por la que fue librado a quien exhiba el cheque en calidad de legítimo tenedor. El librador cuentacorrentista se hace responsable con el beneficiario sino es posible el pago del cheque por intermedio del banco, en otras palabras, si por ejemplo el beneficiario del cheque va al banco y resulta que el cuentacorrentista no tiene fondos, podrá con ese mismo cheque, iniciar un proceso ejecutivo en contra de él, para que se haga responsable de la suma de dinero incorporada en el cheque.

De conformidad con el artículo 730 del C.co, las acciones cambiarias en contra de los obligados en un cheque prescriben en 6 meses desde su presentación. Este artículo debemos concordarlo con el 718 también del C. co. el que precisa los plazos de presentación oportuna de un cheque. Si por ejemplo un cheque es creado o girado en la misma ciudad donde se encuentra el banco donde se encuentra abierta la cuenta corriente, el beneficiario contará con 15 días para hacer una presentación oportuna al banco. Si lo hace dentro de ese término y el cheque no es pagado por el banco, desde ese momento se contarán los 6 meses para que, el legítimo tenedor inicie la acción cambiaria contra el cuentacorrientista librador (o endosantes y avalistas si los hay). Si el cuentacorrientista nunca tuvo fondos disponibles y el beneficiario (siguiendo el ejemplo) presentó el cheque extemporáneamente, los términos de prescripción se comenzarán a contar una vez finalizado el último día en que debió presentarlo (para el ejemplo desde el día 15).

Para terminar, es interesante hacer referencia a la prescripción en los títulos-valores que tienen vencimientos ciertos y sucesivos, o sea, por cuotas o instalamentos y en particular, cuando se incluyen clausulas aceleratorias. De entrada, si un título-valor tiene una forma de vencimiento como esta y no se ha contemplado una clausula aceleratoria, debe decirse sin lugar a dudas, que a cada cuota le corren los términos de prescripción por separado.

Una cláusula aceleratoria es aquella cláusula accidental que se incluye en un título-valor (u otro documento diferente a un título-valor que contenga obligaciones con pagos periódicos ${ }^{30}$ con vencimientos ciertos y sucesivos, para permitir al acreedor en caso de incumplimiento exigir la totalidad de la obligación sin necesariamente tener que esperar a que venzan todas las cuotas. Las cláusulas aceleratorias se dividen en automáticas y facultativas, para decir que las primeras hacen exigibles las obligaciones por cuotas o periódicas por la ocurrencia de un determinado hecho verbigracia el incumplimiento en el pago de una cuota de amortización, caso en el cual este hecho objetivo de manera automática como su nombre lo indica y aún sin manifestación expresa del acreedor la obligación se torna exigible de inmediato. Al paso que la cláusula de aceleración facultativa, como su nombre lo indica, faculta, permite o autoriza al acreedor para acelerar el plazo cuando se genera el incumplimiento por parte del deudor, es decir, ante el incumplimiento del deudor de la obligación no se hace de inmediato exigible sino que precisa del requerimiento hecho por parte del acreedor al deudor en el sentido que se ha extinguido el plazo y por ende está obligado a pagar la totalidad o el saldo insoluto, según el caso (Gómez, 2014).

Si un título-valor con vencimientos ciertos y sucesivos contempla una cláusula aceleratoria automática, desde el primer incumplimiento de inmediato se considera exigible la obligación y, por ende, los términos de prescripción correrán en conjunto 
para toda la obligación, desde ese momento. En cambio, si la clausula aceleratoria es facultativa, deberá esperarse a que el acreedor de manera extrajudicial o judicial $^{31}$ indique desde que momento se hace exigible la obligación para desde este momento, despuntar la prescripción extintiva de la obligación en su totalidad o en su saldo insoluto. Aunque esto último debe matizarse en el sentido que, junto con las cuotas aceleradas, solo pueden adjuntarse aquellas cuotas vencidas a las que no les haya corrido los términos de prescripción. Explico con un ejemplo: Se suscribe un título-valor que debe ser pagado en 10 cuotas de igual valor. Supóngase que el acreedor no ha cobrado las 5 primeras cuotas a las que a cada una le ha corrido el término de 3 años, las que se consideran prescritas. Si hoy quedan cuotas por cobrar, podrá hacer uso de la cláusula aceleratoria, pero solo frente a aquellas que no les haya corrido individualmente los términos de prescripción.

En este mismo sentido también es clara la jurisprudencia. En un caso, un Juez de la República al emitir su sentencia, olvidó analizar en un pagaré con vencimientos y sucesivos la prescripción de las cuotas de manera individual, por lo que su providencia fue objeto de acción de tutela, lo que motivó a que a la Corte Suprema de Justicia la revocara, en sentencia del catorce de septiembre de dos mil diecisiete (M.P. Aroldo Wilson Quiroz Monsalvo):

Así las cosas, evidente se torna la vía de hecho, pues además de que, se itera, el título base de recaudo fue otorgado en pesos mientras que el mandamiento de pago fue librado por una suma de capital en UVR's superior a la pactada en aquel instrumento, lo cierto es que en ese título valor el pago se estableció en cuotas, lo que imponía a la sede judicial criticada examinar el término consagrado en el artículo 789 del Código de Comercio de manera independiente para cada uno de los instalamentos aducidos como adeudados, desde la exigibilidad de los mismos, y en cuanto al saldo acelerado, de ser el caso, a partir de la radicación de la demanda, laborío que no se desplegó en el fallo atacado.

\section{Referencias}

Bejarano, R. (2018). Procesos declarativos, arbitrales y declarativos. Bogotá: Temis.

Calle, B. T. (2006). De los títulos-valores. Tomo I parte general. Bogotá: Leyer.

El Clarín. (19 de 12 de 2012). Policiales. Estafa con un pagaré: Batistuta firmó un autógrafo y quisieron sacarle \$320.000, pág. 1.

Dinero. (4 de 7 de 2018). Infografía. ¿Cuánto le cuesta a Colombia producir sus billetes? pág. 1.

Garrigues, J. (1987). Curso de derecho mercantil. Bogotá: Temis.

Gómez, M. A. (2014). Ensayos sobre el Código General del Proceso. Bogotá: Temis.

León, H. A. (2017). De los Títulos Valores. . Bogotá: Editorial Ediciones Doctrina y Ley.

Ramírez, E. D. (2014). Las tasas de interés en Colombia. Bogotá: Temis.

31. Actualmente el C.G.P. ha establecido en el inciso tercero del artículo 431 que "...Cuando se haya estipulado cláusula aceleratoria, el acreedor deberá pre- 
Rengifo, R., \& Nieto, N. (2010). Literalidad, necesidad, autonomía: atributos de los títulos valores. Análisis de la jurisprudencia de las cortes constitucional y suprema de justicia colombianas 1992-2008. Revista de Derecho. Universidad del Norte, 121-157.

Tena, F. d. (2001). Derecho Mercantil Mexicano. México D.F.: Porrúa.

Valencia, J., \& Garcés, L. R. (2008). Derecho de los títulos-valores. Comentarios jurisprudencia Corte Suprema de Justicia 1972-2008. Bogotá: Universidad Externado de Colombia.

Vivante, C. (1982). Instituciones de derecho comercial. Madrid: Hispana.

\section{Códigos}

Colombia. Consejo Nacional Legislativo. Ley 57 de 1887 Código Civil.

Colombia. Presidencia de la República. Decreto 410 de marzo 27 de 1971, por el cual se expide el Código de Comercio. Bogotá: Diario Oficial 33.339 de junio 16, 1971. Código Civil colombiano.

\section{Leyes}

República de Colombia. Congreso de la República. Ley 45 de 1990.

República de Colombia. Congreso de la República. Ley 599 de 1999.

República de Colombia. Congreso de la República. Ley 1231 de 2008.

\section{Jurisprudencia}

Corte Constitucional. Sentencia T-968 de 2011 (M.P. Gabriel Eduardo Mendoza Martelo.

Consejo de Estado. Auto febrero 21 del 2002. (M.P. Alier Eduardo Hernández Henríquez).

Consejo de Estado. Sentencia del del 31 de enero de 2008 (M.P. Myriam Guerrero de Escobar).

Consejo de Estado. Sentencia de mayo 14 de 2014 (M.P. Enrique Gil Botero).

Corte Suprema de Justicia. Sentencia de marzo 23 de 2017. (M.P. Patricia Salazar Cuéllar).

Corte de Suprema de Justicia. Sentencia del 15 de diciembre de 2015. (M.P. Julio César Valencia Copete).

Corte Suprema de Justicia. Sentencia de tutela del 20 de octubre de 2016. (M.P. Álvaro Fernando García Restrepo).

Corte Suprema de justicia. Sentencia del 14 de septiembre de 2017 (M.P. Aroldo Wilson Quiroz Monsalvo). 